\title{
A study on the kinetic behaviour and thermo-mechanical properties of nanoclay reinforced unsaturated polyester resin prepared under high shear conditions
}

\author{
Mehdi Poorabdollah, Mohammad Hosain Beheshty, ${ }^{*}$ Mehdy Vafayan \\ *Department of Composite, Iran Polymer and Petrochemical Institute, P.O. Box: \\ 14965/115, Tehran, I.R. Iran; fax: +98 21 44580023; e-mail: m.beheshty@ippi.ac.ir.
}

(Received: 21 April, 2009; published: 07 April, 2012)

\begin{abstract}
Kinetic behaviour and thermo-mechanical properties of composites based on unsaturated polyester (UP) resin and organically modified clay (OMC) are completely dependent on their preparation procedure. The investigation on the preparation procedure of the UP/OMC suspensions under high shear conditions alone (shear rate $=4.86 \times 10^{4} \mathrm{~s}^{-1}$ ) without interference of chemical compatibility of OMC with UP resin on the intercalation and exfoliation processes has been the main aim of the present work. Reaction rate and degree of conversion of UP/3wt\%OMC mixtures prepared at three mixing speeds of 1000,3000 and 5000 $\mathrm{rpm}$ and several mixing times ranging from $15 \mathrm{~min}$ to $12 \mathrm{~h}$ showed an abnormal behaviour. The results showed a little decrease in the reaction rate and degree of conversion when mixing time increased from $1.5 \mathrm{~h}$ to $12 \mathrm{~h}$ at $1000 \mathrm{rpm}, 1.5 \mathrm{~h}$ to 4.5 $\mathrm{h}$ at $3000 \mathrm{rpm}$ and $30 \mathrm{~min}$ to $3 \mathrm{~h}$ at $5000 \mathrm{rpm}$. Thermo-mechanical properties of composites showed maximum values for storage modulus when plotted against the mixing time. Reaction rate, degree of conversion and morphology of UP/OMC composites indicated that cure reaction is affected by the extent of expansion of interlayer space of the OMC, the number of the expanded interlayer spaces per volume unit and the number of broken clay agglomerates.
\end{abstract}

\section{Introduction}

Nowadays it is evident that clay nanolayers bring about unique properties for various polymeric systems including unsaturated polyester resins. Naturally occurring clay soils are very hydrophilic and as a result they are not highly compatible with unsaturated polyester resins. To enhance the interfacial interaction between nanoclay and organic polymer it is necessary to modify the surface of clay with organic compounds. Polymer-layered silicate nanocomposites are in fact nanometric dispersions having far better properties than conventional composites or the same micro-composites. Recently special attention has been paid to the properties of nanocomposites. These properties include physical and mechanical properties [1, 2], thermal and electrical properties [3, 4], flame retardancy [5-7], gas barrier properties $[8,9]$ and shrinkage control behaviour [10-14].

There is a great variety of layered silicates but few of them have been found suitable to be used as layered polymer-silicate nanocomposites among which we can refer to montmorillonite, MMT, (a type of clay called aluminosilicate smectic clay). In this type of clay the silicate layers can separate from each other more easily [15].

Distribution of nanoclay particles in polymer matrix results in three types of composites. They are identified as immiscible or the same micro-composite, 
intercalated nanocomposite and exfoliated nanocomposite. In immiscible nanocomposite the basal spacing of nanoclay does not change. In various intercalated nanocomposites the d-spacing is increased and this indicates that polymer has entered between layers. And at last in exfoliated nanocomposites the $d$ spacing is increased so much that the original structural order of clay is not observed any more [16].

Although UP resins are the mostly used thermosets, the nanocomposites based on UP and organically modified clays have been studied less than other nanocomposites. Shu et al. [17] studied the mechanism of formation of UP/MMT nanocomposite and realized that the mixing method can be effective on cross-link density of cured UP. Mixing method with high shear levels for prolonged durations causes high intercalation levels accompanied by exfoliation of silicate layers and better dispersion of clay particles [18]. It has been confirmed that at constant temperature the presence of nanoclay does not affect the final resin conversion [10], but it plays the role of a co-promoter in copolymerization reaction between UP oligomers and styrene monomers and decreases the induction time.

Zhou et al. [19] studied the behavior of curing of UP nanocomposites through inclusion of the $\mathrm{C}=\mathrm{C}$ double bonds in the layers of modified montmorillonite. Their results showed that by adding nanoclay the gel time and activation energy of the cure reaction increase. In fact they proved that due to presence of $\mathrm{C}=\mathrm{C}$ double bonds in the layers of modified montmorillonite the curing mechanism changes. The comparison between the cure reaction of neat UP and UP containing $1 \%$ MMT was done by $X$ in et al. [20] and they verified that the relative conversions of UP $\mathrm{C}=\mathrm{C}$ bonds and styrene $\mathrm{C}=\mathrm{C}$ bonds increases as time passes. For neat UP, when the conversion of $\mathrm{C}=\mathrm{C}$ bonds is higher than $25 \%$ the relative conversion of styrene is higher than UP, but for UP containing $1 \% \mathrm{MMT}$, the same situation occurs until the conversion of $\mathrm{C}=\mathrm{C}$ bonds is over $65 \%$. During a research [21] it was indicated that dispersion procedure of nanoclay particles in UP matrix is dependent on process of chemical modification of nanoclay.

Adding an OMC with nonpolar modifier, namely Cloisite 20A, to UP resin is aimed to investigate the effect of high shear conditions alone without interference of chemical compatibility of Cloisite 20A with UP resin on the intercalation and exfoliation processes. In this experimental work UP/OMC composites were prepared by an entirely new method. At first a pre-suspension of OMC in UP was prepared during a long procedure and then the pre-suspensions were diluted and were exposed to a high shear level. Morphology of the composites was studied with TEM and XRD. Curing kinetics of samples containing 2 and $3 w t \%$ OMC and thermo-mechanical properties of UP/OMC composites prepared under various shearing conditions and for several time durations were investigated.

\section{Results and Discussion}

\section{Selection of OMC concentration}

Fig. 1a shows the DSC reaction rate of neat UP resin and UP resin filled with 2 and $3 w t \% 20 \mathrm{~A}$ as a function of reaction time for samples which have been exposed to high shear level at $55^{\circ} \mathrm{C}$ for $3 \mathrm{~h}$ at $5000 \mathrm{rpm}$ (shear rate $=4.86 \times 10^{4} \mathrm{~s}^{-1}$ ). The reaction peak of UP/3wt $\% 20 \mathrm{~A}$ is higher than that of the UP/2wt\%20A. It can be attributed to the catalyzing role of OMC. As Fig. 1a shows, the induction time of samples is 
decreased by increasing OMC concentration. The reason is presence of higher density of catalyzing particles in sample containing $3 \mathrm{wt} \%$ OMC. In Fig. $1 \mathrm{~b}$ the degree of cure of samples containing 2 and $3 \mathrm{wt} \% 20 \mathrm{~A}$ has been compared with that of neat UP at 5000rpm and $3 \mathrm{~h}$ mixing time. The final degree of cure has been increased in UP/3wt\%20A up to $20 \%$.

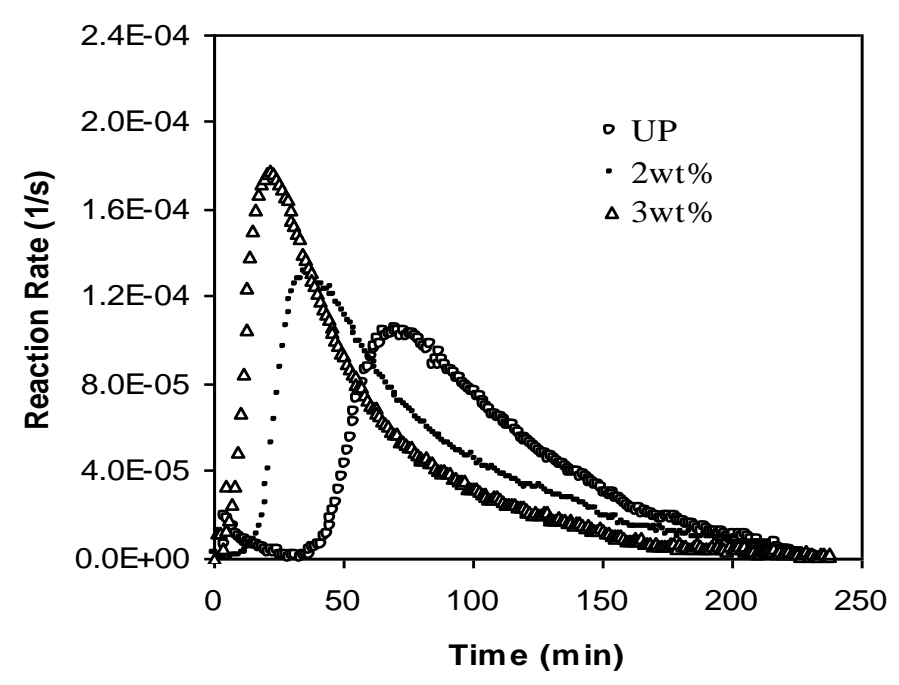

(a)

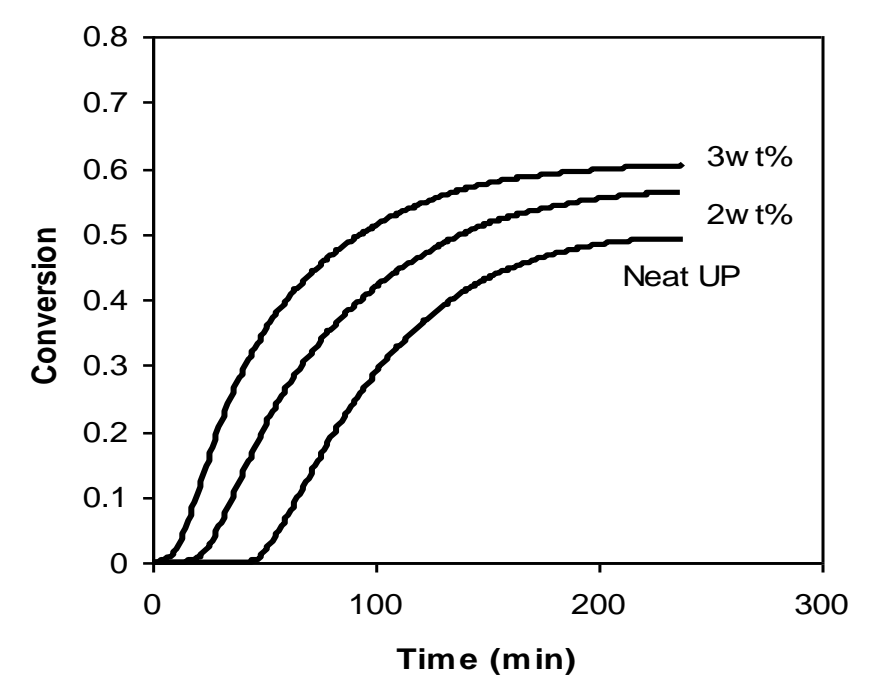

(b)

Fig. 1. Reaction rate (a) and conversion profile (b) of UP resin containing 2 and $3 w t \%$ $20 \mathrm{~A}$ prepared at $55^{\circ} \mathrm{C}$ for $3 \mathrm{~h}$, at $5000 \mathrm{rpm}$.

For showing this fact whether this trend continues or not due to the lengthening of mixing time we lengthened the mixing time up to $12 \mathrm{~h}$. In Fig. 2a the reaction rate of samples containing 2 and 3wt\% 20A has been shown in the mixing speed of 5000 rpm for $12 \mathrm{~h}$ mixing duration. The trend is similar to the previous one (Fig. 1a) but the reaction peak difference between UP/3wt\%20A and UP/2wt\%20A for $12 \mathrm{~h}$ is 1.6 times that for $3 \mathrm{~h}$. As a result we can conclude that the number of effective catalyzing particles has been increased due to the increase of mixing time. The increase of effective surface area of OMC layers is not only caused by exfoliation and 
intercalation processes but it is also directly related to the percentage of OMC. The final conversion has reached 0.7 in the sample containing $3 w t \%$ of $20 \mathrm{~A}$ when the mixing time has lasted for $12 \mathrm{~h}$ (Fig. 2b).

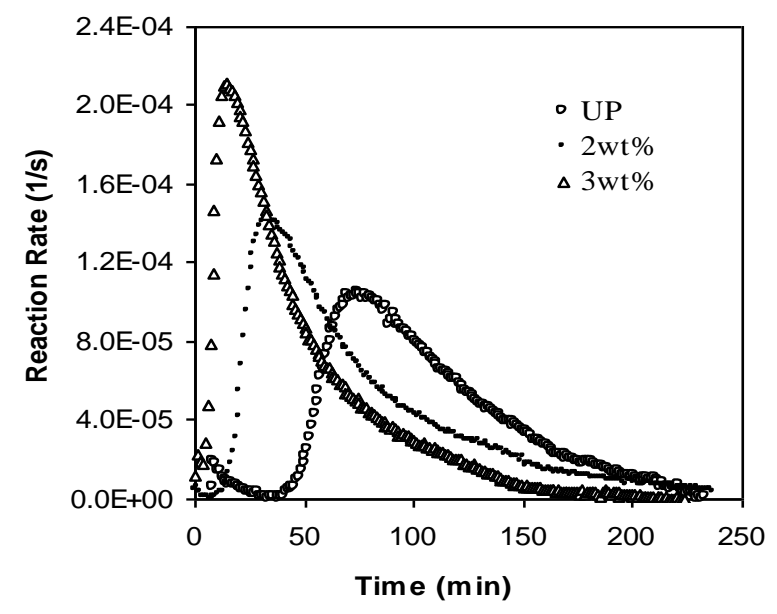

(a)

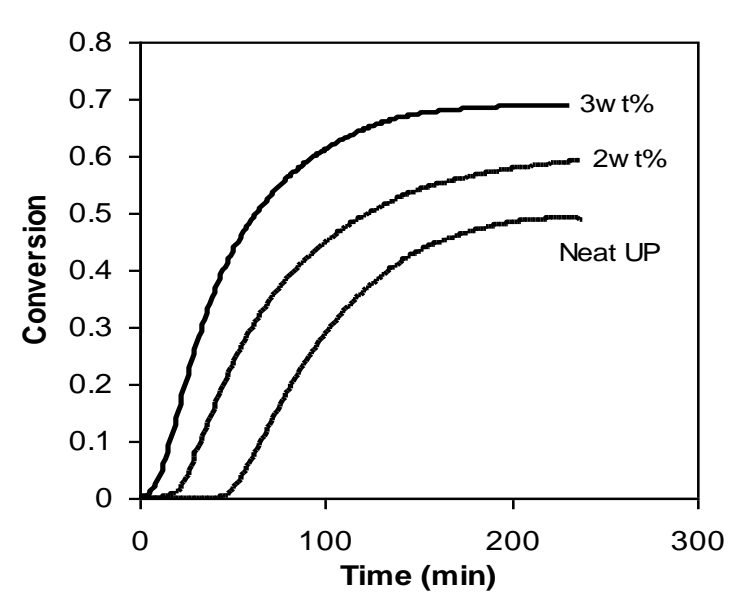

(b)

Fig. 2. Reaction rate (a) and conversion profile (b) of UP resin containing 2 and 3 wt $\% 20 \mathrm{~A}$ prepared at $55^{\circ} \mathrm{C}$ for $12 \mathrm{~h}$, at $5000 \mathrm{rpm}$.

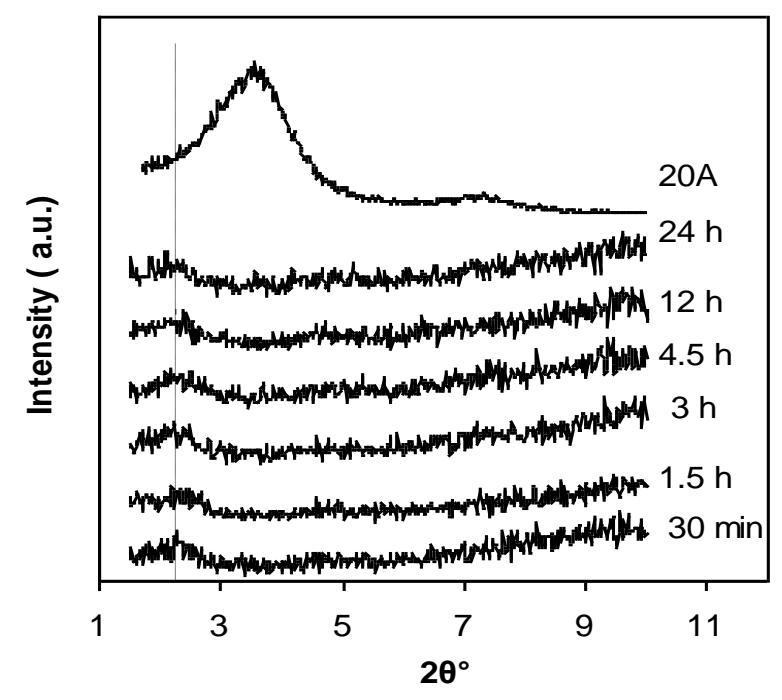

Fig. 3. XRD patterns of composites containing $2 \mathrm{wt} \% 20 \mathrm{~A}$ prepared at $5000 \mathrm{rpm}$ for mixing times between $30 \mathrm{~min}$ and $24 \mathrm{~h}$.

Fig. 3 shows $X$ - ray diffraction patterns of composites containing $2 \mathrm{wt} \% 20 \mathrm{~A}$ prepared at 5000rpm for mixing times of $30 \mathrm{~min}, 1.5,3,4.5,12$, and $24 \mathrm{~h}$. For all samples except the $24 \mathrm{~h}$ mixed sample the interlayer spacing is $37.3 \AA$ which shows $13 \AA$ increase in comparison with $24.3 \AA$ for pure Cloisite $20 \mathrm{~A}$. After $24 \mathrm{~h}$ of mixing the interlayer spacing has reached $41.5 \AA$.

Fig. 4 depicts the XRD patterns for the composites containing 3wt\% 20A for mixing times between 0 min (pre-suspension) and $12 \mathrm{~h}$. After $12 \mathrm{~h}$ almost no characteristic peak is observed and as a result we can expect that ordered structure has been so little that XRD patterns have not been able to record it. The XRD results of 
composites containing 2 and $3 w t \%$ OMC show that the degree of intercalation and exfoliation in the composite with higher OMC content is larger. Therefore, in the continuation of work on the study of kinetic behaviour and thermo-mechanical properties of UP/OMC composites we decided to use samples with higher OMC concentration, i.e. $3 \mathrm{wt} \%$ OMC.

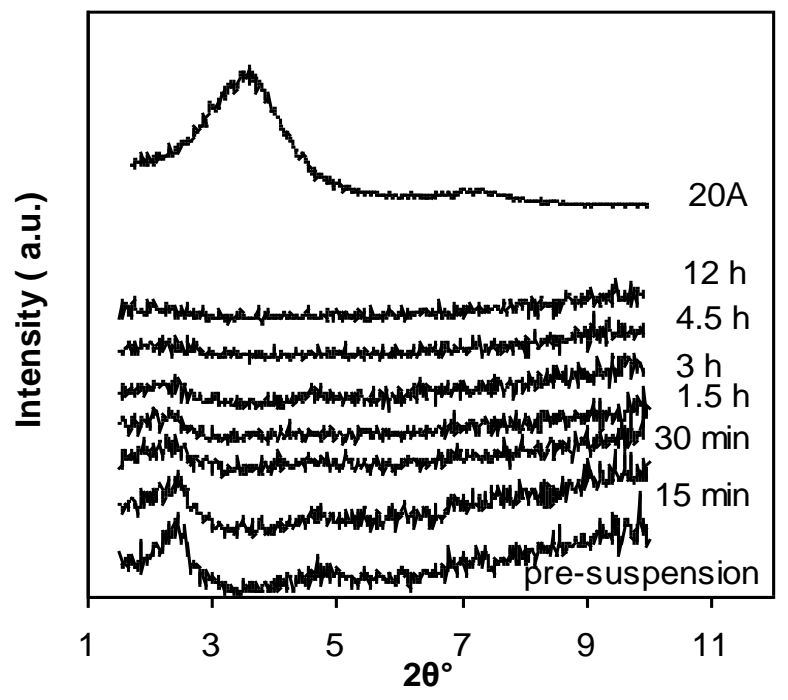

Fig. 4. XRD patterns of composites containing $3 \mathrm{wt} \% 20 \mathrm{~A}$ prepared at $5000 \mathrm{rpm}$ for mixing times between 0 min and $12 \mathrm{~h}$.

\section{Morphology of composites}

Fig. 5a shows low magnification TEM image of the pre-suspension containing $3 \mathrm{wt} \%$ nanoclay 20A. Primary clay particles on a micro scale indicate that the particles have not been broken. By applying high shear up to $12 \mathrm{~h}$ the particles have been broken and this event has been clearly illustrated in Fig $5 \mathrm{~b}$. Due to poor dispersion of the clay particles, the UP/3wt\%20A samples are not considered as nanocomposites.

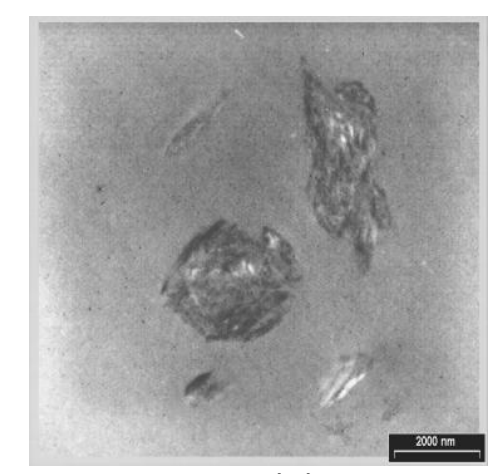

(a)

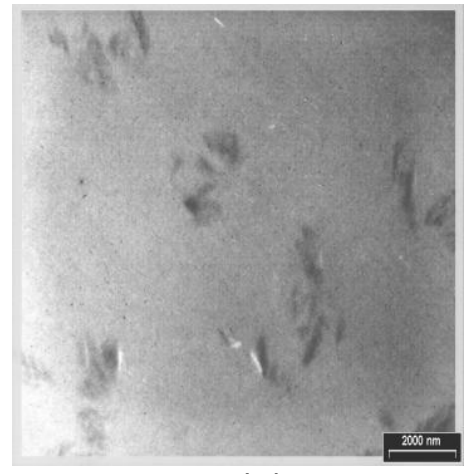

(b)

Fig. 5. Low magnification TEM images of composites prepared at $5000 \mathrm{rpm}$ for (a) pre-suspension and (b) suspension mixed under high shear condition for $12 \mathrm{~h}$.

They may be better defined as microcomposites since clay particles scale is in micrometers rather than nanometers. The clay particles are poorly dispersed because the chemical structure of 20A modifier is nonpolar (dimethyl 
dehydrogenated tallow quaternary ammonium) but polyester backbone of UP resin has a polar nature.

Fig. 6 shows high magnification TEM images of composites containing 3wt\% 20A prepared at $5000 \mathrm{rpm}$ for various mixing times. It is clearly evident that in all samples the intercalation of silicate layers is precisely observed. Due to lengthening of the mixing time the d-spacing has been increased in the large intercalated regions. In TEM image for $12 \mathrm{~h}$ mixing time we can even observe exfoliated single layers caused by breaking of small intercalated clay layer tactoids.

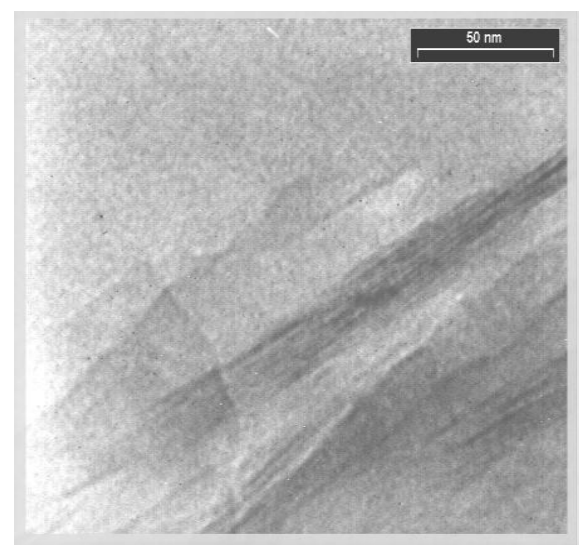

(a)

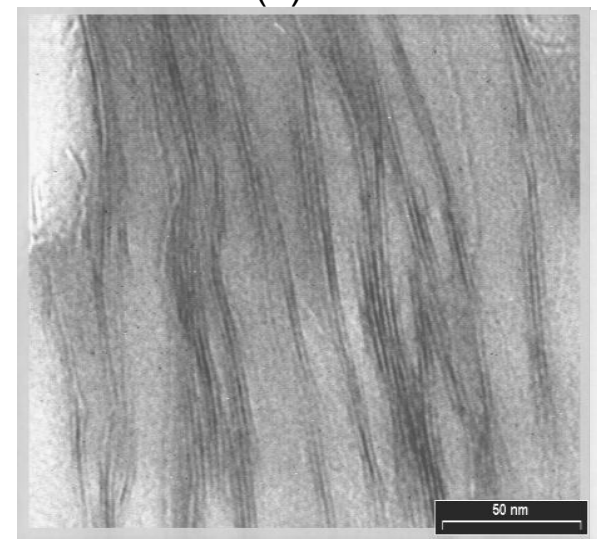

(c)

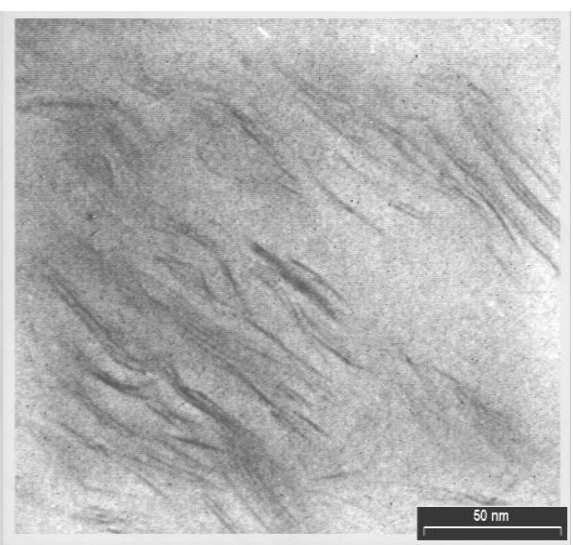

(b)

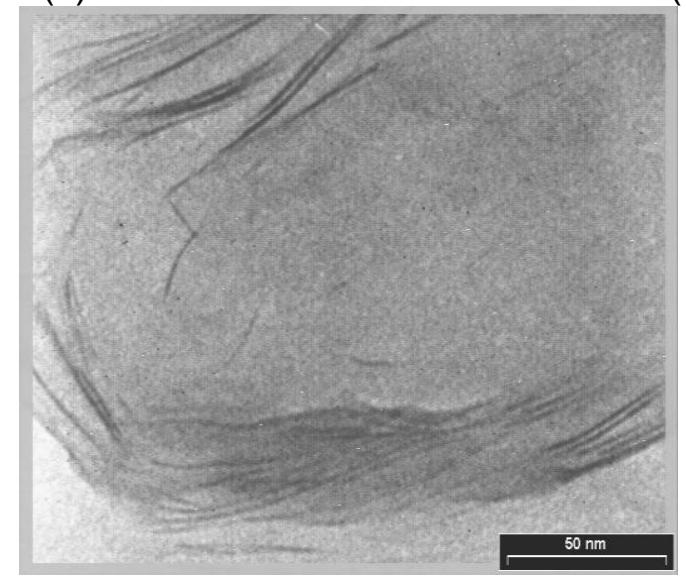

(e)

Fig. 6. High magnification TEM images of composites prepared at $5000 \mathrm{rpm}$ for several mixing times; (a) presuspension, (b) $30 \mathrm{~min}$, (c) $1.5 \mathrm{~h}$, (d) $4.5 \mathrm{~h}$, (e) $12 \mathrm{~h}$. 


\section{Effect of mixing speed and mixing time on the kinetic behaviour}

In Fig. 7 a reaction rates of UP/3wt\%20A suspensions have been shown for samples prepared at $1000 \mathrm{rpm}$ mixing speed for various mixing times. The presence of $20 \mathrm{~A}$ as $\mathrm{OMC}$ has resulted in increase of reaction rate of suspensions compared with that of neat UP but what is more considerable is the fact that first the highest peak of reaction belongs to the $1.5 \mathrm{~h}$ mixed suspension and second there is a little difference between the reaction rate profiles related to the pre-suspension and $15 \mathrm{~min}$ mixed suspension.

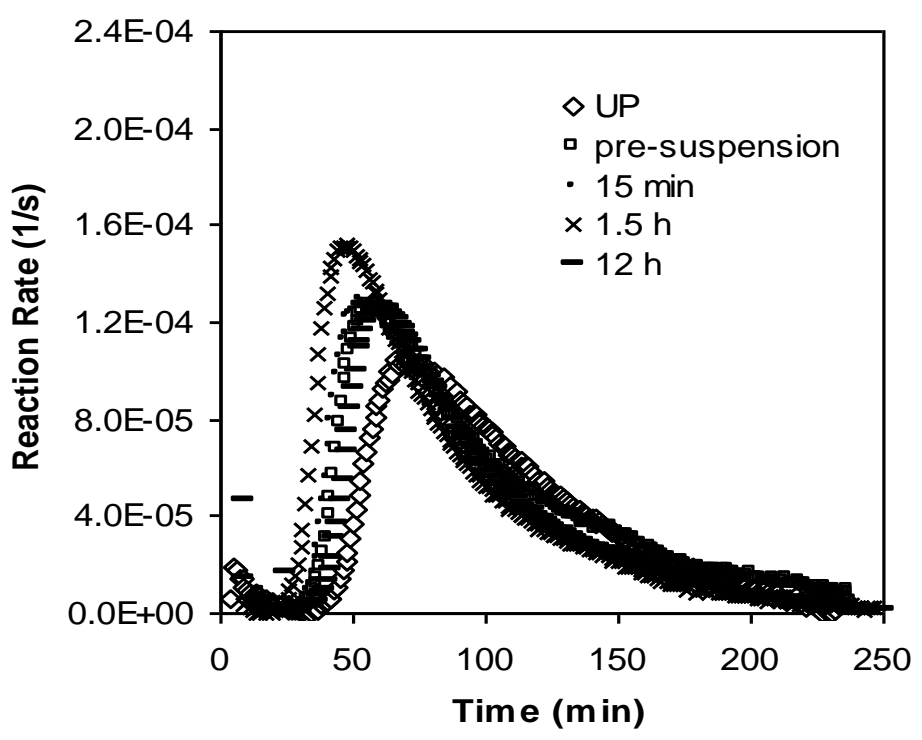

(a)

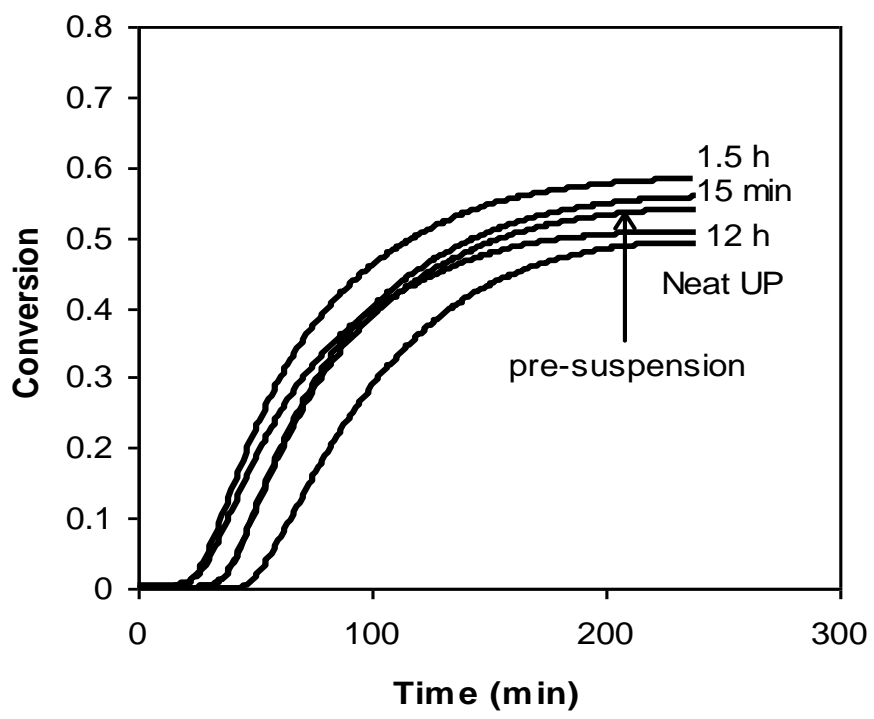

(b)

Fig. 7. Reaction rate (a) and conversion profile (b) of UP / 3wt $\% 20 \mathrm{~A}$ suspensions prepared at $1000 \mathrm{rpm}$ in various mixing times.

The similarity of reaction rate profiles related to the pre - suspension and $15 \mathrm{~min}$ mixed suspension indicates that 15 min mixing duration is not enough. Decrease of 
reaction rate for $12 \mathrm{~h}$ mixed suspension seems unreasonable. It should be stressed here that the overall reaction rate of UP/3wt\%20A suspension is affected by the diffusion rate of initiator into the clay galleries and the effective concentration of initiator that penetrates into the clay galleries [22, 23]. If more silicate layers are intercalated but no breaking of clay agglomerates has occurred, the diffusion of initiator into the silicate interlayer spacing is limited. Therefore, this can be the reason of reaction rate reduction despite increasing mixing time up to $12 \mathrm{~h}$.

Conversion profiles of UP/3wt\%20A suspensions prepared at $1000 \mathrm{rpm}$ for various mixing times have been shown in Fig $7 \mathrm{~b}$. The final conversion changing trend is similar to the changing trend that observed for the peaks illustrated in Fig 7a. This indicates that the effective concentration of initiator in the clay galleries is limited for $12 \mathrm{~h}$ mixed sample, therefore the final conversion of this sample is lower than that of other samples except neat UP.

In Fig. 8 reaction rate of UP/3wt\%20A suspension has been shown for samples prepared at $3000 \mathrm{rpm}$ for various mixing times. Although the difference of the reaction rates between the pre-suspension and 15 min mixed sample is not so great, but increase of their reaction rates has been considerable compared to that of neat UP. This matter indicates that even pre-suspension has the intercalated and exfoliated structures. It is evident that in $1.5 \mathrm{~h}$ mixed sample the reaction rate has increased in peak point up to $1.5 \times 10^{-4} \mathrm{~s}^{-1}$. This can be caused by excessive expansion of $\mathrm{OMC}$ galleries and increasing their catalyzing role. But it can seen that the increase of reaction rate of $12 \mathrm{~h}$ mixed sample has not been considerable compared to that of $1.5 \mathrm{~h}$ mixed sample (Fig. 8b). A little decrease of reaction rate in $4.5 \mathrm{~h}$ mixed sample can be due to intercalation of a higher number of silicate layers which, in turn, caused insufficient diffusion of initiator into the interlayer spaces of OMC structures. This unusual reduction in the reaction rate was also seen in Fig $7 \mathrm{a}$ for $12 \mathrm{~h}$ mixed sample. The difference between the maximum reaction rates of $1.5 \mathrm{~h}$ mixed sample and $12 \mathrm{~h}$ mixed sample that are shown in Fig $7 \mathrm{a}$ is $0.23 \times 10^{-4} \mathrm{~s}^{-1}$ while, the difference between the maximum reaction rates of $1.5 \mathrm{~h}$ mixed sample and $4.5 \mathrm{~h}$ mixed sample that are shown in Fig $8 \mathrm{~b}$ is only $0.04 \times 10^{-4} \mathrm{~s}^{-1}$.

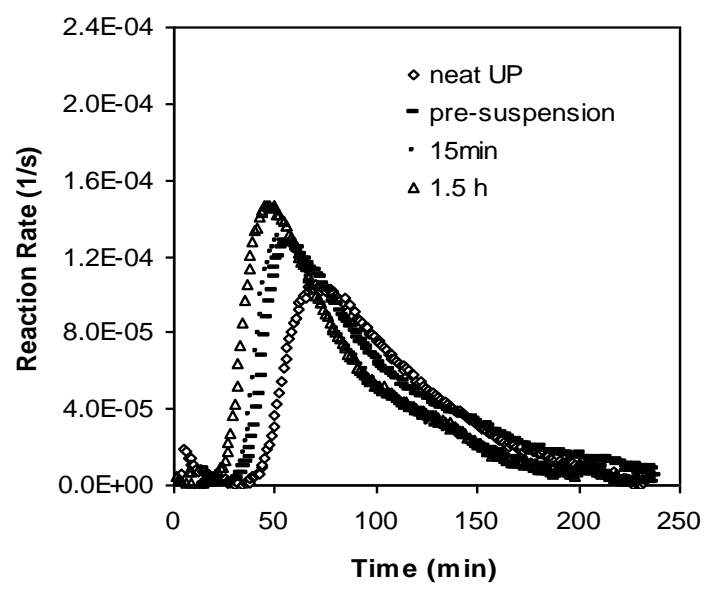

(a)

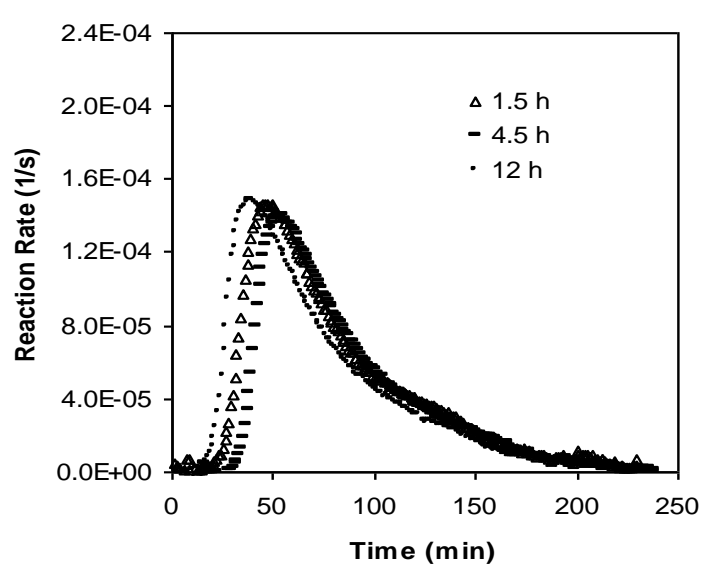

(b)

Fig. 8. Reaction rate of UP/ 3wt\%20A suspensions prepared at $3000 \mathrm{rpm}$ in various mixing times. 
Conversion profiles of UP/3wt\%20A suspensions prepared at $3000 \mathrm{rpm}$ for various mixing times have been shown in Fig. 9. The results show that an increase in mixing time up to $1.5 \mathrm{~h}$ increased the reaction conversion to 0.6 . Nevertheless, the final conversion for $4.5 \mathrm{~h}$ and $12 \mathrm{~h}$ mixed samples has decreased compared to that of 1.5 $\mathrm{h}$ mixed sample. This unusual reduction in the conversion was also seen in Fig. $7 \mathrm{~b}$ for $12 \mathrm{~h}$ mixed sample.

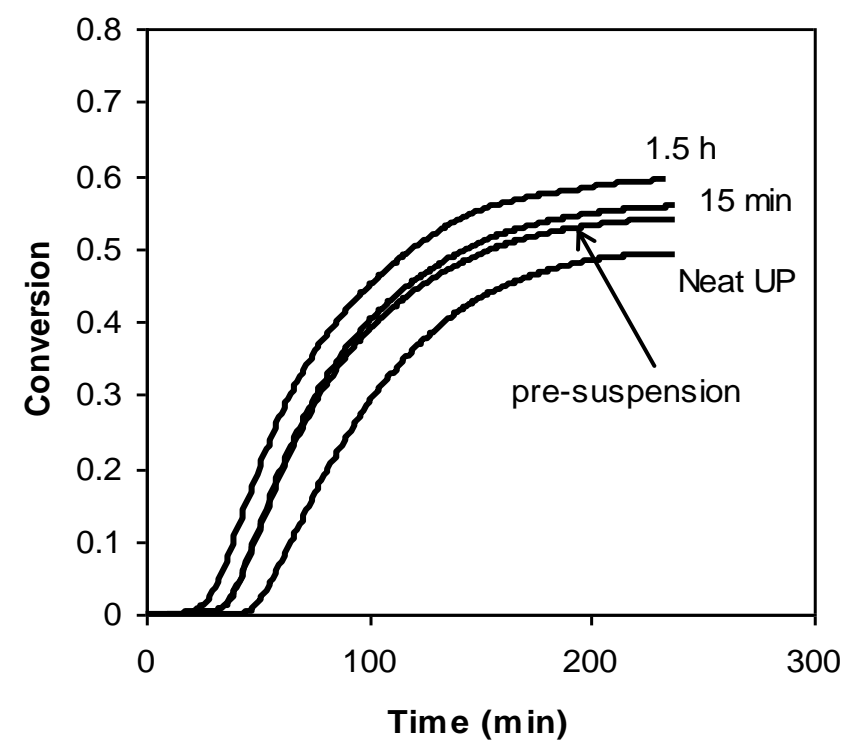

(a)

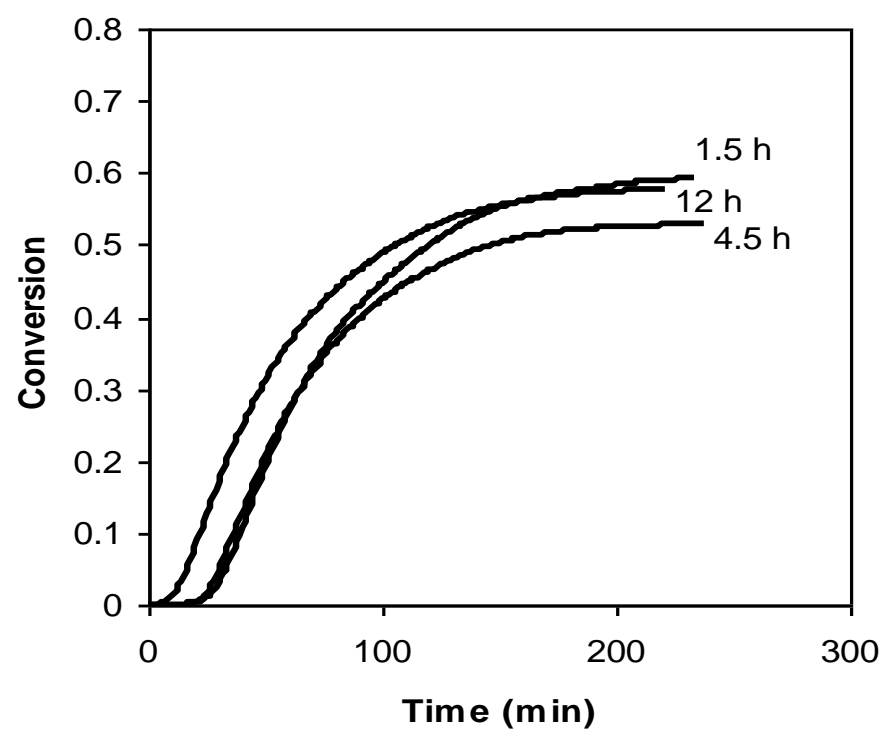

(b)

Fig. 9. Conversion profile of UP/ 3wt\%20A suspensions prepared at $3000 \mathrm{rpm}$ in various mixing times.

There are three main factors that can be effective on the reaction rate of UP/OMC composite formation. (a) The extent of expansion of interlayer space; (b) The number of the expanded interlayer spaces per volume unit: (c) The number of broken clay agglomerates. 
If the extent of expansion of interlayer space is increased, the reaction rate will be higher because this is equivalent to an increase of the amount of catalyst in the system. But if the high level shear stress results in expansion of a higher number of interlayer spaces the overall reaction rate decreases and it is expected that the degree of final conversion is also decreased. It should be noted that when the number of the expanded interlayer spaces per volume unit is increased, the diffusion of initiator molecules into the interlayer spaces is limited and therefore the overall reaction rate is decreased. If the applied stress is greatly increased the possibility of breakdown of clay agglomerates is increased and if the OMC particles get finer it will leave an effect equivalent to an increase of the effective clay surface area. As a result the abnormal behavior of reaction rates observed in Figs 7, 8 and 9 is due to second factor which leaves a negative effect on reaction rate.

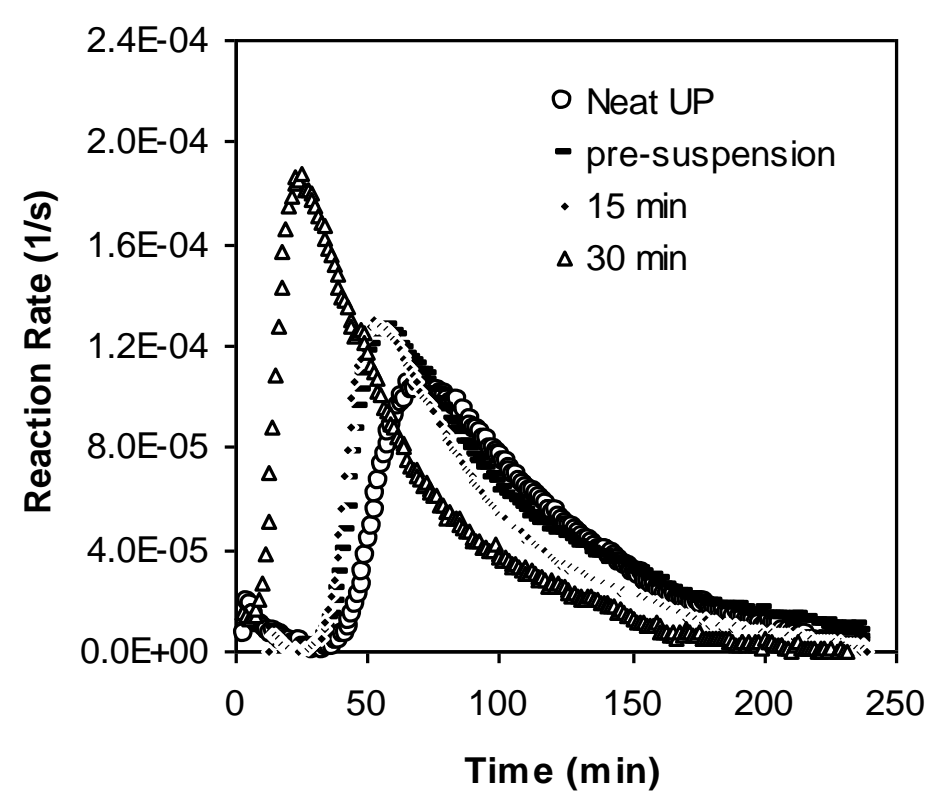

(a)

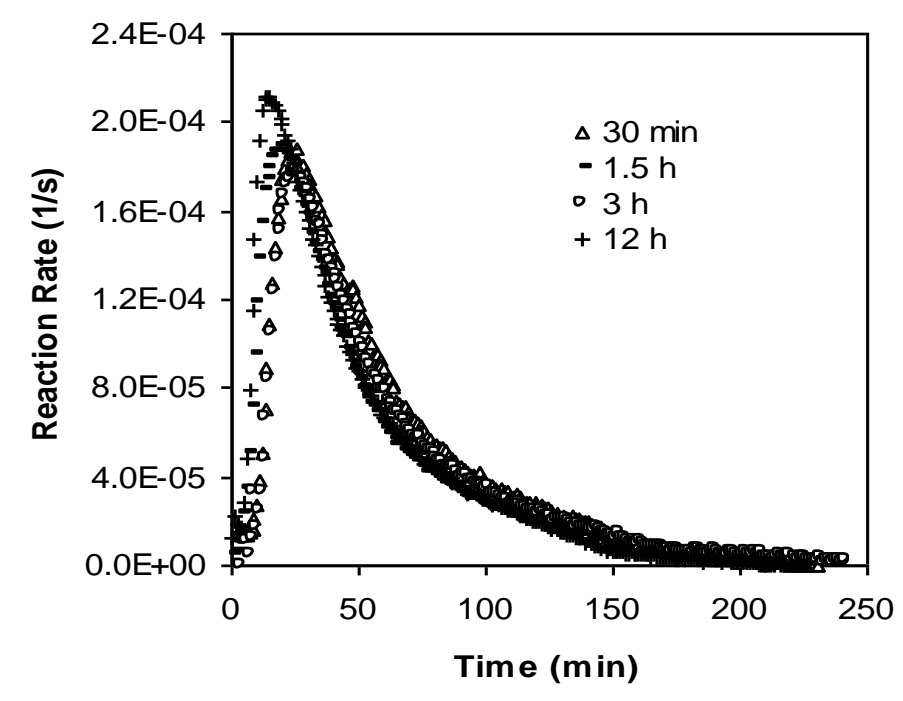

(b)

Fig. 10. Reaction rate of UP/ 3wt\%20A suspensions prepared at $5000 \mathrm{rpm}$ in various mixing times. 
In Fig. 10 the reaction rate of formation of composites containing 3wt $\% 20 \mathrm{~A}$ has been shown for $5000 \mathrm{rpm}$ mixing speed in various mixing times. Again we observe that the change of reaction rate for pre-suspension and 15 min mixed suspension compared to that of neat UP is almost the same and consequently this change is caused by the presence of intercalated and exfoliated regions in pre-suspension. We must pay attention that in the preparation of pre-suspension the nanoclay has been put in contact with polyester resin for a long time ( 5 days).

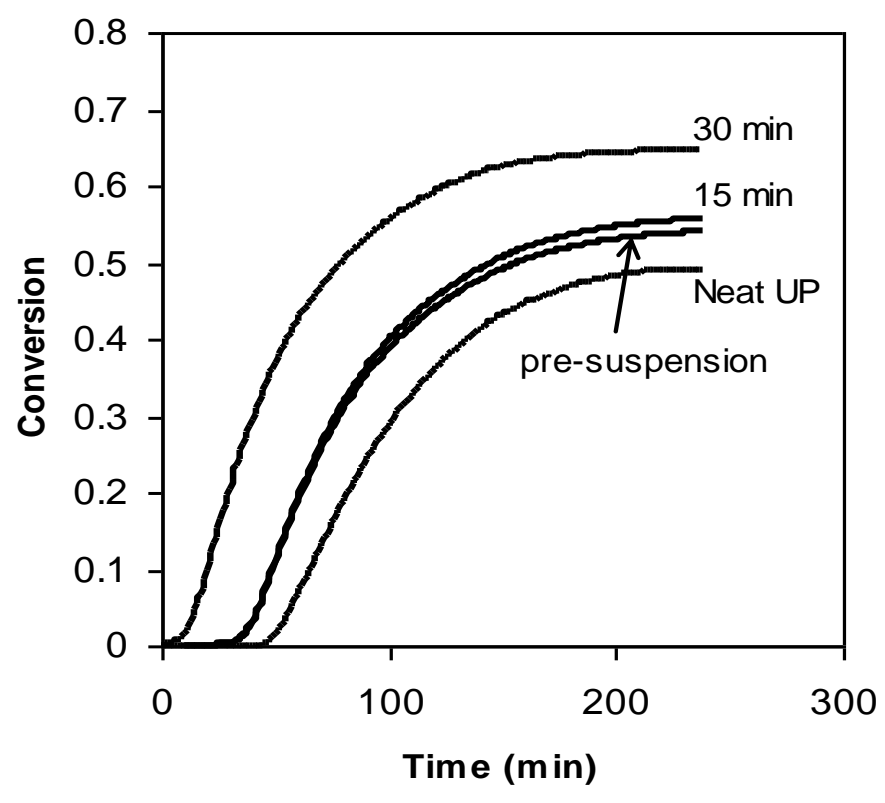

(a)

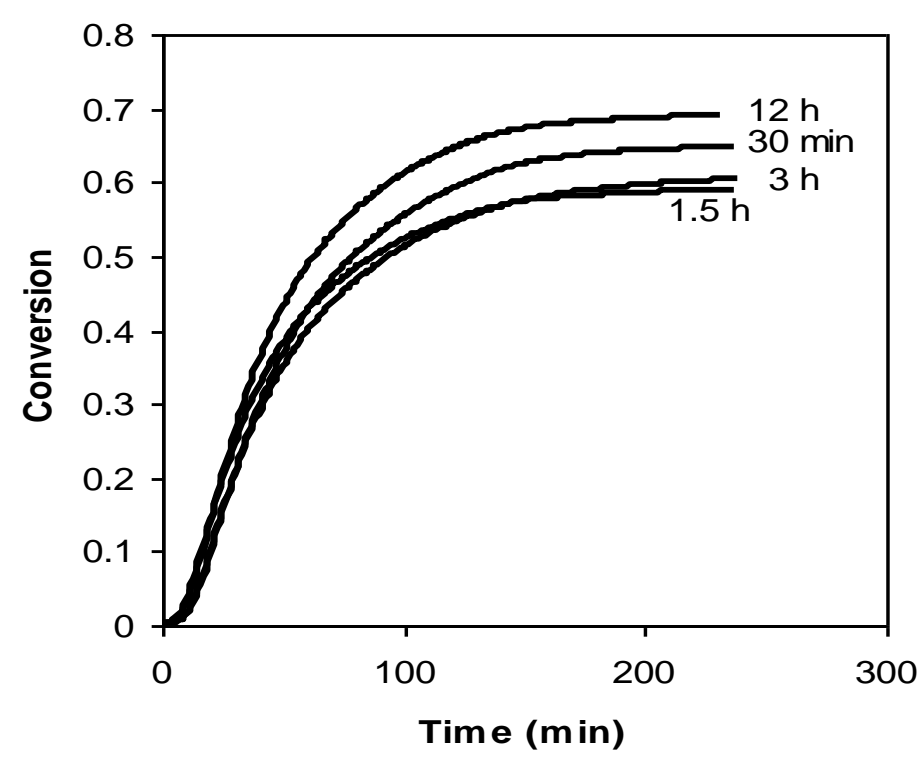

(b)

Fig. 11. Conversion profile of UP/ 3wt\%20A suspensions prepared at $5000 \mathrm{rpm}$ in various mixing times.

The trend of increasing reaction rate with mixing time for this mixing speed is similar to $3000 \mathrm{rpm}$ mixing speed but the difference is the fact that the time of sudden 
change of reaction rate has decreased from $1.5 \mathrm{~h}$ to $30 \mathrm{~min}$. This difference is due to higher shear stress level in $5000 \mathrm{rpm}$ mixing speed which accelerates the intercalation and exfoliation processes. Furthermore increasing of the maximum cure rate of $30 \mathrm{~min}$ mixed sample relative to that of neat UP is higher by $23 \%$ than that of reported by Xu [24]. As we can see in Fig 10 a considerable change has not occurred in the reaction rate due to the increase of the mixing time up to $1.5 \mathrm{~h}$ and $3 \mathrm{~h}$. The reason behind this is the fact that a higher number of layers have been intercalated. More intercalation and no further breakdown of clay agglomerates have caused formation of some long galleries that initiator molecules do not penetrate. Therefore, with lengthening of mixing time up to $3 \mathrm{~h}$ the reaction rate is not considerably increased. But with lengthening of mixing time up to $12 \mathrm{~h}$ the reaction rate is increased up to a considerable amount and its reason is ever-increasing breakdown of clay agglomerates.

Conversion profiles of UP/3wt\%20A suspensions prepared at $5000 \mathrm{rpm}$ for various mixing times have been shown in Fig 11. The results show that an increase in mixing time up to $30 \mathrm{~min}$ increased the reaction conversion to 0.66 . Nevertheless, the final conversion for $1.5 \mathrm{~h}$ and $3 \mathrm{~h}$ mixed samples has decreased compared to that of 30 min mixed sample (by approximately 10\%). The presence of a higher number of intercalated layers and creation of zigzag structures have made the diffusion of initiator molecules more difficult into the interlayer spaces and consequently it has decreased the effective concentration of initiator and has lowered the degree of conversion.

\section{Thermo-mechanical properties}

The storage modulus and loss factor of neat UP and UP/3wt $\% 20 \mathrm{~A}$ composites prepared at $5000 \mathrm{rpm}$ in $0 \mathrm{~min}$ (pre-suspension), $15 \mathrm{~min}, 30 \mathrm{~min}, 1.5 \mathrm{~h}, 3 \mathrm{~h}$ and $12 \mathrm{~h}$ mixing times are presented in Fig 12 . Storage modulus at $40{ }^{\circ} \mathrm{C}$, storage modulus at $\left(T_{g}+50\right){ }^{\circ} \mathrm{C}$, glass transition temperature and peak factor calculated from DMTA curves are illustrated in Figs 13, 14 and 15.

Fig. 13 shows the storage moduli of neat UP and UP/3wt\% 20A composites prepared at 1000, 3000 and $5000 \mathrm{rpm}$ as a function of mixing time. The storage modulus measured from DMTA curves at $40{ }^{\circ} \mathrm{C}$ is shown in Fig 13 (a) for samples prepared at various mixing speeds. Theoretical and experimental results have been shown that the addition of small amount of nanoclay additives to thermoset resins produced a large increase in the storage modulus relative to the value of unfilled resins $[25,26]$. It is reported that the storage modulus of OMC filled UP resin is affected by the type and concentration of OMC. The storage modulus of neat UP is increased in the range of from about $13.4 \%$ to about $16.8 \%$ by filling with $2.5 \%$ of different nanoclays [21]. As Fig 13a shows, the storage modulus of neat UP at $40{ }^{\circ} \mathrm{C}$ as a function of mixing time is increased in the range of 8.0 to $17.4 \%$ and 7.4 to $24.6 \%$ for the UP/3wt\% $20 \mathrm{~A}$ composites prepared at 3000 and $5000 \mathrm{rpm}$ respectively. After $12 \mathrm{~h}$ mixing, the storage modulus of neat UP at $40{ }^{\circ} \mathrm{C}$ for UP/3wt\% $20 \mathrm{~A}$ composite prepared at $1000 \mathrm{rpm}$ speed increased to $7.3 \%$. The plots in Fig13a show a maximum storage modulus at $1.5 \mathrm{~h}$ and $4.5 \mathrm{~h}$ mixing time for the composites prepared at $5000 \mathrm{rpm}$ and $3000 \mathrm{rpm}$ respectively. By increasing of mixing time to 12 $\mathrm{h}$ it is seen that the storage modulus at $40^{\circ} \mathrm{C}$ for 5000 and $3000 \mathrm{rpm}$ is decreased by $0.8 \%$ and $1.8 \%$ with respect to their maximum values, respectively. The enhancement of storage modulus strongly depends on the interaction of the UP chains and clay particles. When polymer matrix is reinforced with rigid filler particles 
the polymer interface adjacent to the clay particle is highly restrained mechanically. Platelets edges (of the clay particles) act as a weak point and are sites of high stress concentration of the matrix. As the aspect ratio of the filler increases these weak points are decreased which results in the higher amount of stress transfer between the matrix and filler particles. Active surface area of filler increases due to intercalation of the polymer chains inside the clay galleries. Polymer chains inside the clay galleries are immobilized and the effective immobilization of these chains is responsible for the enhancement of the storage modulus [27].

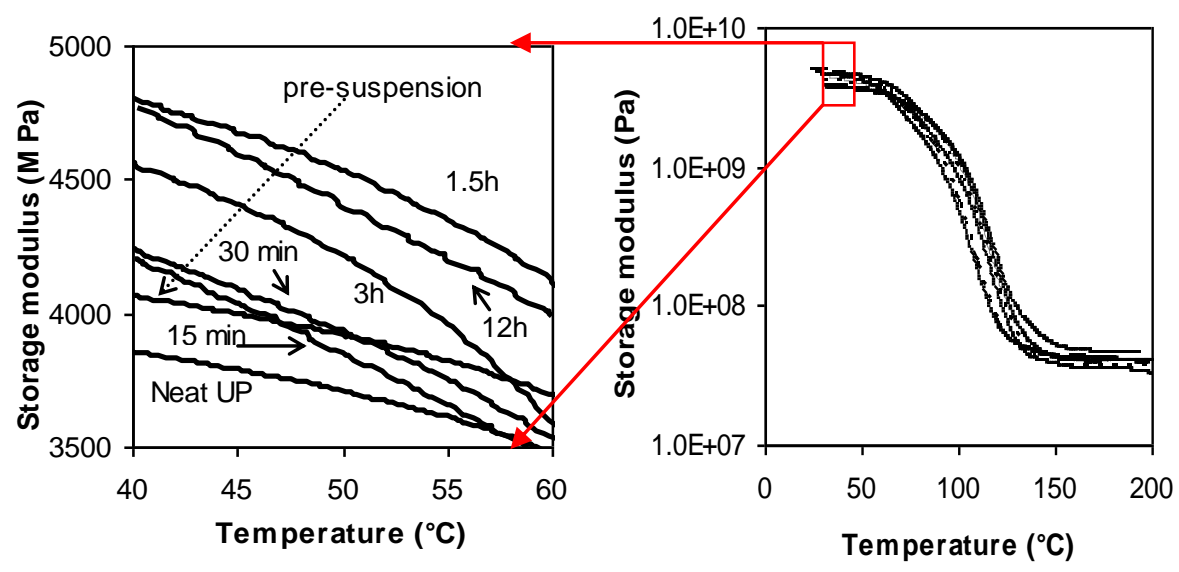

(a) Storage modulus

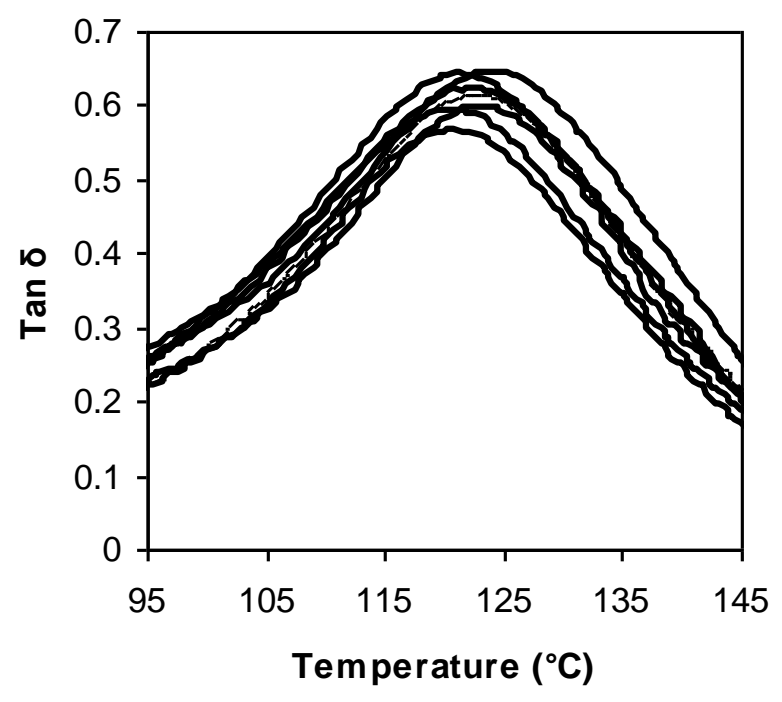

(b) Loss factor

Fig. 12. Examples of DMTA curves of UP/ 3wt $\% 20 \mathrm{~A}$ composites prepared at 5000 rpm in various mixing times.

Fig. $13 \mathrm{~b}$ shows the storage modulus of the UP/3wt $\% 20 \mathrm{~A}$ composites as a function of mixing time at $\left(T_{g}+50\right)^{\circ} \mathrm{C}$ at various mixing speeds. As Fig 13b shows, the trend of changing of the storage modulus at $\left(T_{g}+50\right){ }^{\circ} \mathrm{C}$ verses mixing time at three mixing speeds is similar to those observed for the storage modulus at $40{ }^{\circ} \mathrm{C}$. The storage modulus increased from 36.3 to $48.3 \mathrm{MPa}$ in $5000 \mathrm{rpm}$ after $1.5 \mathrm{~h}$ and to $45.5 \mathrm{MPa}$ in $3000 \mathrm{rpm}$ after $4.5 \mathrm{~h}$, representing $33.0 \%$ and $25.3 \%$ improvements, respectively. Therefore, the reinforcing effect of the clay nanoplatelets on storage modulus above 
the glass transition temperature due to increasing of shear stress level was observed.

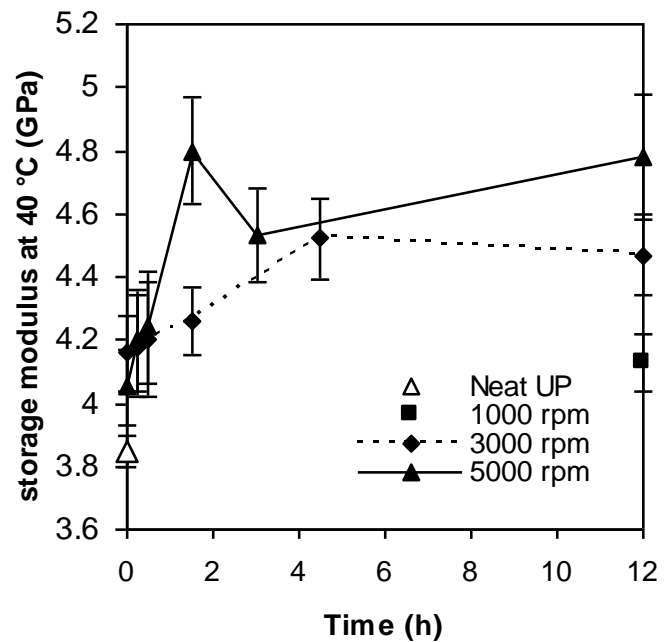

(a)

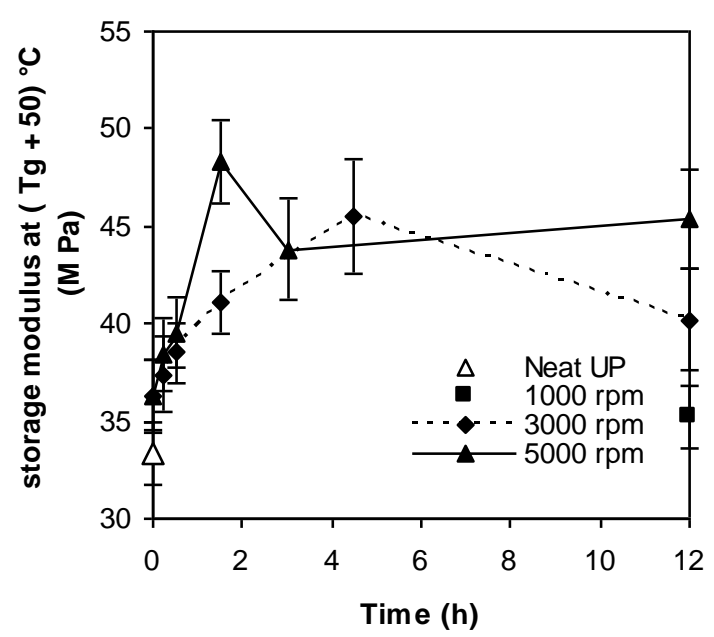

(b)

Fig. 13. Storage modulus of UP/ $3 w t \% 20 \mathrm{~A}$ composites (a) at $40{ }^{\circ} \mathrm{C}$ and (b) at $\left(\mathrm{T}_{\mathrm{g}}+\right.$ 50) ${ }^{\circ} \mathrm{C}$ as function of mixing time.

Fig. 14 shows the glass transition temperature of neat UP and UP/3wt\% $20 \mathrm{~A}$ composites as a function of mixing time in 1000, 3000 and $5000 \mathrm{rpm}$. The glass transition temperature was constant regardless of the mixing speed and mixing time. This suggests that the cross linking reaction takes place homogeneously inside and outside of the silicate layers that is due to using a long term five step procedure for preparation of pre-suspensions.

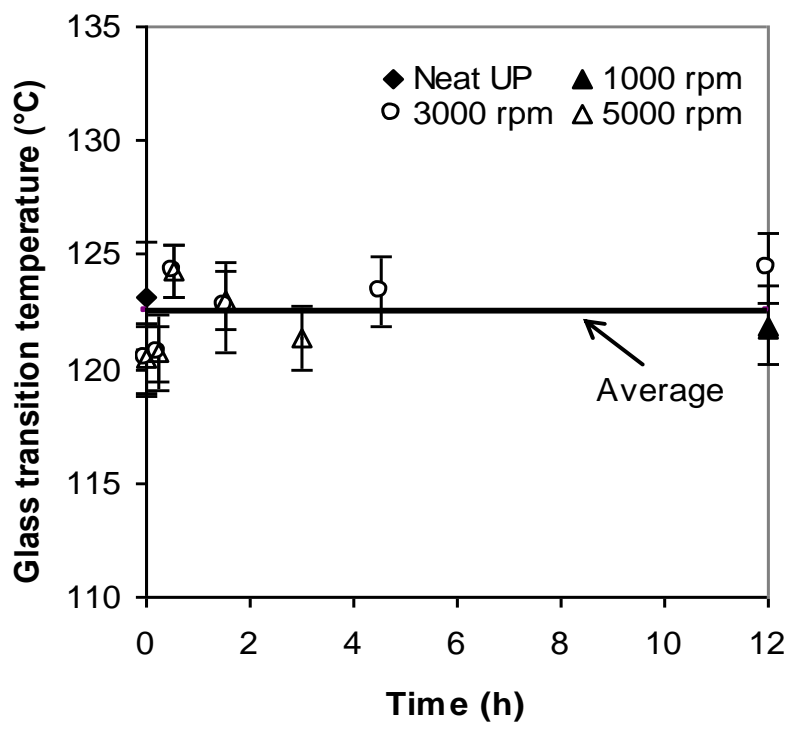

Fig. 14. Glass transition temperature of neat UP and UP/ 3wt $\% 20 \mathrm{~A}$ composites as function of mixing time at three mixing speeds.

The symmetric peak of loss factor presented in Fig 12b suggests complete cure of the neat UP and UP/3wt\% 20A composites. The $\mathrm{T}_{\mathrm{g}}$ was assigned as the temperature 
where loss factor was a maximum. The peak factor is defined as the value of full width at half maximum (FWHM) divided by height of the peak and can give a qualitative assessment of the homogeneity of the polymer network and the distribution of the molecular weight. Fig. 15 shows peak factor as function of mixing time at 1000, 3000 and $5000 \mathrm{rpm}$ for neat UP and UP/3wt\% 20A composites. Although the mixing time and mixing speed are increased, there is no considerable change in the peak factor.

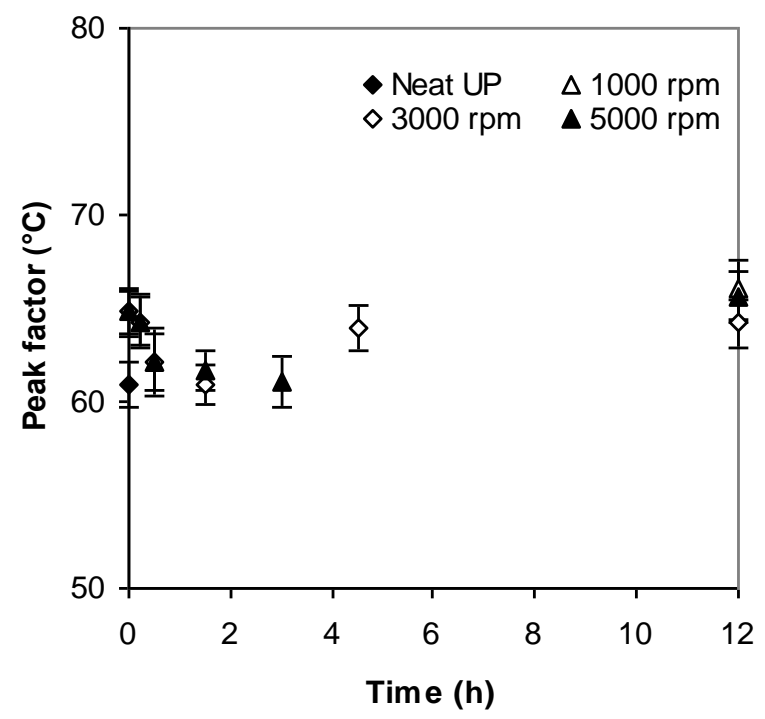

Fig. 15. Peak factor of neat UP and UP/ 3wt\% $20 \mathrm{~A}$ composites as function of mixing time at three mixing speeds.

\section{Conclusions}

Preparation of UP/OMC suspensions through the application of high shear forces in a special rotor / stator dispersing system showed that the high shear condition can mostly affect the extent of intercalation and delamination processes and change the kinetics of curing reaction and morphology of clay reinforced UP resin in compliance with mixing speed and mixing time.

Cloisite 20A used as OMC could completely affect the kinetics of curing in 3wt\%. The reaction rate and the degree of conversion of UP/3wt $\% 20 \mathrm{~A}$ and UP/2wt $\% 20 \mathrm{~A}$ are higher than the reaction rate and the degree of conversion of neat UP. The XRD results showed that for UP/3wt\% 20A composite there is a mixing time for which XRD pattern does not show any diffraction peak but this state was not observed for composite containing $2 \mathrm{wt} \%$ of $20 \mathrm{~A}$. The effect of mixing time on morphology of composites by TEM proved that with increasing the mixing time the clay agglomerates get finer and the OMC gallery spacing broadens and the extent of exfoliation increases.

The relationship between mixing time and kinetic behavior of composites showed an abnormal behavior which is a reflection of events of breakdown of layered structure of clay and change of $d$-spacing of OMC nanoplatelets. The high shear forces in suspensions in which clay agglomerates move freely enabled us to increase the dspacing and the number of intercalated layers of nanoplatelets and to crash and break the agglomerates more and more. 
The plot of storage modulus (at $40^{\circ} \mathrm{C}$ ) verses mixing time showed that there are maximum values at $1.5 \mathrm{~h}$ and $4.5 \mathrm{~h}$ mixing time for the composites prepared at 5000 $\mathrm{rpm}$ and $3000 \mathrm{rpm}$, respectively. The trend of changing of the storage modulus at $(\mathrm{Tg}$ $+50)^{\circ} \mathrm{C}$ verses mixing time at two mixing speeds was similar to that observed for the storage modulus at $40^{\circ} \mathrm{C}$. The glass transition temperature was constant regardless of the mixing speed and mixing time. This suggests that the cross linking reaction takes place homogeneously inside and outside of the silicate layers that is due to using a long - time five step procedure for preparation of pre-suspensions.

\section{Experimental}

\section{Materials and measurements}

The unsaturated polyester resin used in this study was an ortho UP resin containing $38 \%$ by weight styrene (BUSHEPOL 81715 , Bushehr chemical Industry), with an average of 3.4 vinylene groups per unsaturated polyester molecules. The average molecular weight of the unsaturated polyester resin is 1589 and the equivalent molecular weight/ (mole $\mathrm{C}=\mathrm{C}$ ) is 464 . The molar ratio of styrene/unsaturated polyester resin is 2.7 with the average viscosity of $450 \mathrm{cP}$ at $23{ }^{\circ} \mathrm{C}$. Cloisite ${ }^{\circledR} 20 \mathrm{~A}$ $(20 \mathrm{~A})$ is a natural montmorillonite modified with $2 \mathrm{M} 2 \mathrm{HT}$ (dimethyl dehydrogenated tallow quaternary ammonium) chloride used as OMC. 20A is an OMC from Southern Clay. The initiator was methyl ethyl ketone peroxide (MEKP) $(50 \%$ in phthalate plasticizer) containing 9.9\% active oxygen supplied by Pamokale Co. The promoter used was cobalt naphthanate, CoN (10\% in White spirits, Chekad Co.). Hydroquinone (HQ, Merck) was used as inhibitor.

The calorimetric measurements were done on a NETZSCH DSC 200 F3 differential scanning calorimeter operating in a nitrogen atmosphere. The sample of $25 \mathrm{mg}$ of UP/20A suspension with 2 or $3 w t \%$ OMC was placed into the aluminum sample pan and isothermal experiments were performed at $25{ }^{\circ} \mathrm{C}$. The reaction was not considered complete. Therefore, isothermal experiments followed by a dynamic experiment from 25 to $250{ }^{\circ} \mathrm{C}$ with a heating rate of $5{ }^{\circ} \mathrm{C} / \mathrm{min}$ to determine the residual heat. The total reaction exotherm was calculated from the area under the isothermal and dynamic DSC curves. Reaction rate and conversion as a function of time were calculated by using the exotherm data and with this assumption that the total reaction exotherm is equal to $100 \%$ conversion.

Dynamic mechanical thermal properties of all UP/20A composites were measured using a dynamic mechanical thermal analyzer (DMTA-Triton) with a three-point bend fixture at the condition of $1 \mathrm{~Hz}, 0.05 \mathrm{~mm}$ displacement and -30 to $200{ }^{\circ} \mathrm{C}$ range. The DMTA specimens (10 $\mathrm{mm}$ long, $7.5 \mathrm{~mm}$ wide and $2-2.7 \mathrm{~mm}$ thick) were cut from the composite samples.

$\mathrm{X}$-ray diffraction $(\mathrm{XRD})$ patterns of the composites were recorded by monitoring the diffraction angle $2 \theta$ from $1.5^{\circ}$ to $10^{\circ}$ on a Philips X'PERT X-ray diffraction system using $\mathrm{CuK}_{\alpha}$ radiation source at a generator voltage of $40 \mathrm{kV}$ and a generator current of $40 \mathrm{~mA}(\lambda=1.5405 \hat{A})$. The XRD specimens $(20 \mathrm{~mm} \times 20 \mathrm{~mm} \times 2.2 \mathrm{~mm})$ were cut from the composite samples.

Transmission electron microscopy (TEM) was performed on ultramicrotomed sample prepared using a Reichert OMU3 microtome equipped with a diamond knife and mounted on 200 mesh copper grids. The section was cut to a thickness of $\sim 70 \mathrm{~nm}$. 
TEM observation was performed on a Philips CM 200 FEG using an accelerating voltage of $200 \mathrm{kV}$.

\section{Preparation of pre-suspensions and composites}

The required amount of $20 \mathrm{~A}$ in powder form was put in a $50 \mathrm{ml}$ beaker and then the UP resin was added very slowly to it and a radial flow stirrer (diameter of $29 \mathrm{~mm}$ with eight $9 \mathrm{~mm}$ width rectangular blades) fixed $1.5 \mathrm{~cm}$ above the surface of the powder mass. The mixture remains stationary for $24 \mathrm{~h}$ at $50{ }^{\circ} \mathrm{C}$ (first step) and then the mechanical mixing was applied at $85 \mathrm{rpm}$ for $24 \mathrm{~h}$ (second step). The mixture remained stationary to allow removing of air bubbles. In the third step, the stirrer was fixed at $0.5 \mathrm{~cm}$ above the powder mass and the mechanical mixing was again applied at $85 \mathrm{rpm}$ for $24 \mathrm{~h}$. At this step a highly-viscous gel was collected in the boundary layer of the powder mass. The position of stirrer in the beaker had come close to the surface of the powder mass to disperse the viscous gel and generate a new fresh surface layer. The viscous gel is formed due to rapid diffusion of the styrene monomers into the organo-modified layered silicate framework. The distance of stirrer from the surface of the powder mass was chosen by experimental trial and error. In the fourth and fifth steps, the mixing was continued at $185 \mathrm{rpm}$ for $24 \mathrm{~h}$ and $400 \mathrm{rpm}$ for $24 \mathrm{~h}$ respectively. The five-step procedure as that mentioned above was used to prepare the pre-suspension of the UP and OMC. The phase separation did not occur in pre-suspension after two weeks.

The pre-suspension containing 10wt $\% 20 \mathrm{~A}$ was diluted by adding pure UP resin up to 2 and $3 w t \%$ and the diluted suspensions were subjected to high shear mixing at three velocities (1000, 3000, and $5000 \mathrm{rpm}$ ) using a homogenizer, equipped with a powerful dispersing aggregate, at $55^{\circ} \mathrm{C}$ for several durations up to $12 \mathrm{~h}$. A radial flow stirrer was installed next to the dispersing aggregate in order to make the suspension homogeneous and to prevent formation of vortexes near to the dispersing aggregate.

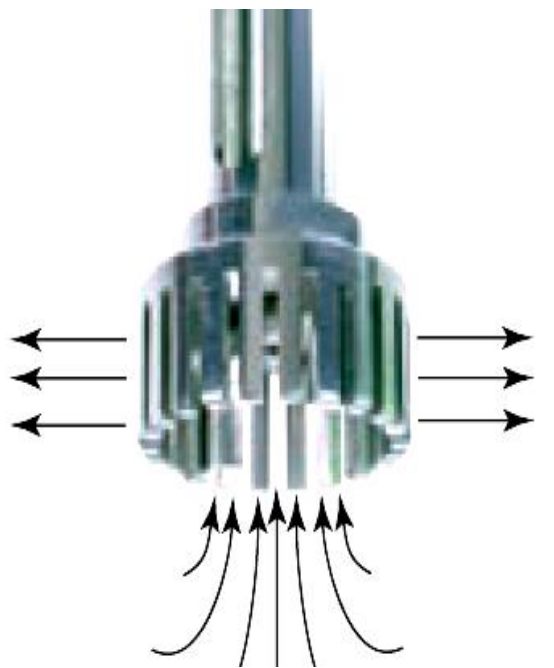

(a)

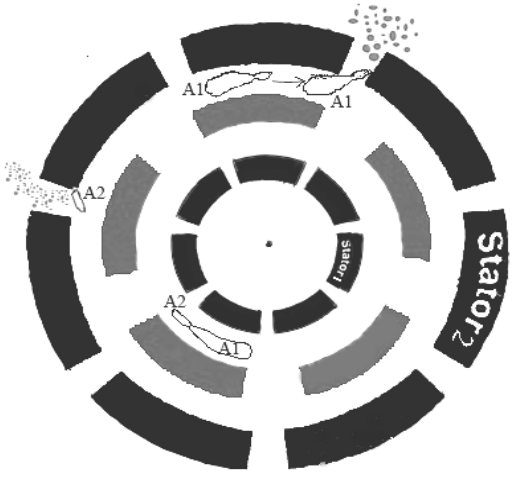

(b)

Fig. 16. (a) Flow pattern of pre-suspension stream which passes through the dispersing aggregate. (b) Breaking mechanism of the large clay agglomerates which pass through the gap between stator (black) and rotor (gray) [28].

As Fig 16a shows, pre-suspension is dragged in the central part located at the lower part of the dispersing aggregate and is guided out through slots of outer part located 
on circumference of the aggregate. If the speed of aggregate is $5000 \mathrm{rpm}$ some vortexes are created and these vortexes prevent pre-suspension from dragging in and guiding out.

For clarification of breaking mechanism of nanoclay particles you can view the Fig 16b. Suppose that we have the particle A which is an agglomerate of nanoclay is located in the space between stator 1 and rotor. Great speed (rpm) of rotor causes high shear stress and causes the particle $A\left(A_{1}+A_{2}\right)$ to be dragged and broken into two particles $A 1$ and $A 2$. After passing through the slots of rotor the particle $A 1$ or $A 2$ hits the blades of stator 2 due to very high centrifuge force and this particle is broken into smaller particles. Since the gap between rotor and stator is very small, the very intensive shear force is applied on the layered structure of clay.

The resin mixture used to prepare the UP/20A composites contains $1.5 \mathrm{wt} \% \mathrm{MEKP}$, $0.4 \mathrm{wt} \% \mathrm{CoN}, 300 \mathrm{ppm} \mathrm{HQ}$, and 2 and 3wt\% 20A. The resin mixture was cured at room temperature for $24 \mathrm{~h}$. Post-curing was performed for $2 \mathrm{~h}$ at $100{ }^{\circ} \mathrm{C}$.

\section{Acknowledgements}

The authors would like to acknowledge the financial support of Iran National Science Foundation (INSF) of this research project (grant no. 84076/2).

\section{References}

[1] Giannelis, E.P. Adv Mater. 1996, 8, 29.

[2] Inceoglu, A.B.; Yilmazer, U. Poly Eng \& Sci. 2003, 43, 661.

[3] Gyoo, P.M.; Venkataramani, S.; Kim, S.C. J Appl Polym Sci. 2006, 101, 1711.

[4] Pan, Y.X.; Yu, Z.Z.; Ou, Y.C.; Hu, G.H. J Polym Sci: Polym Phys. 2000, 38, 1626.

[5] Morgan, A.B.; Polym Adv Tech. 2006, 17, 206.

[6] Morgan, A.B.; Chu, L.L.; Harris, J.D. Fire Mate. 2004, 29, 213.

[7] Nazare, S.; Kandola, B.K.; Horrocks, A.R. Polym Adv Tech. 2006, 17, 294.

[8] Bharadwaj, R.K.; Mehrabi, A.R.; Hamilton, C.; Trujillo, C.; Murga, M.; Fan, R.; Chavira, A.; Thompson, A.K. Polymer 2002, 43, 3699.

[9] Lange, J.; Wyser, Y. Pack Tech Sci. 2003, 16, 149.

[10] Xu, L.; Lee, L.J. Polymer 2004, 45, 7325.

[11] Cao, X.; Lee, L.J. Society of Plastics Engineers Annual Technical Conference, ANTEC, Conference Proceeding. 2005, 4, 348.

[12] Beheshty, M.H.; Vafayan, M.; Poorabdollah, M. Polym Compos. 2009, 30, 629.

[13] Beheshty, M.H.; Vafayan, M.; Poorabdollah, M. Iranian Polym J. 2006, 15, 841.

[14] Khanbashi, A.A.; Gamal, M.E.; Moet, A. J Appl Poly Sci. 2005, 98, 767.

[15] Yei, D.R.; Fu, H.K.; Chen, W.Y.; Chang, F.C. J Polym Sci: Polym Physics. 2006, $44,347$.

[16] Morgen, A.B.; Gilman, J.W. J Appl polym Sci. 2003, 87, 1329.

[17] Suh, D.J.; Lim, Y.T.; Park, O.O. Polymer 2000, 41, 8557.

[18] Harpaz, I.M.; Narkis, M.; Siegmann, A. Annual Technical Conference- ANTEC, Conference Proceedings. 2005, 4, 353.

[19] Zhou, Y.; Yang, X.; Jia, D. Polym int. 2007, 56, 267.

[20] Xin, W.L.; Yi, H.; Li, R.; Ge, L.P. Polym Mat Sci Eng. 2005, 21, 209.

[21] Miyagawa, H.; Mohanty, A.K.; Burgueno, R.; Drzal, L.T.; Misra, M.; Nanosci, J. Nnanotech. 2006, 6, 464.

[22] Kornmann, X.; Lindberg, H.; Berglund, L.A. Polymer 2001, 42, 4493.

[23] Kornmann, X.; Lindberg, H.; Berglund, L.A. Polymer 2001, 42, 1303. 
[24] Xu, L.; Lee, L.J. Polym Eng Sci. 2005, 45, 496.

[25] Miyagawa, H.; Rich, M.J.; Drzal, L.T. J. Polym. Sci: Polym. Phys. 2004, 42, 4391.

[26] Miyagawa, H.; Foo, K.H.; Daniel, I.M.; Drzal, L.T. J Appl polym Sci. 2005, 96, 281.

[27] Mishara, J.K.; Hwang, K.J.; Ha, C.S. Polymer 2005, 46, 1995.

[28] Kinematica, A.G. Dispersing and Mixing Technology, Technical Catalogue. 